\title{
Solvent Blend Performance in Hydrocarbon Recovery from Nigerian Tank Bottom Sludge
}

\author{
Elijah A. Taiwo ${ }^{1, a *}$, John A. Otolorin ${ }^{2, b}$ \\ ${ }^{1}$ Department of Chemical Engineering, Obafemi Awolowo University, Ile-Ife, Osun State, 220005, \\ Nigeria. (234)08033840833 \\ ${ }^{2}$ Department of Chemistry and Industrial Chemistry, Bowen University, Iwo, Osun State, 220005, \\ Nigeria. (234)07035666707 \\ aetaiwo@oauife.edu.ng, eataiwo@yahoo.com, bjaotolorin@gmail.com
}

Keywords: Tank bottom sludge (TBS), Oil recovery, Solvent extraction, Hydrocarbon content, Solvent blend.

\begin{abstract}
Oil sludge waste associated with crude oil production generally consists of oil, sands and untreatable emulsions segregated from the production stream, and sediment accumulated on the bottom of crude oil and water storage tanks. The use of single solvent and combination (solvent blend) was evaluated for extraction of hydrocarbon content (oil) of the Tank Bottom Sludge (TBS) associated with the crude oil production with a view to optimizing hydrocarbon recovery from the sludge. TBS samples were contacted with selected solvents blends of varying volumetric ratios, each at a time. The blend generated from xylene, hexane, cyclohexane and petroleum ether representing aliphatic and aromatic interactive combination with varying polarity. Their effects on the oil recovery from tank bottom sludge were determined, with solubility parameter as a factor. The optimum oil recovery by blend $A, B$ and $C$ at room temperature of $29^{\circ} \mathrm{C}$, from sample 1 are respectively $54.48 \%(3: 2), 60.33 \%(2: 3)$ and $61.10 \%$ (1:1); from Sample 2, were respectively $66.25 \%(2: 3), 60.80(3: 2)$ and $63.35(1: 1)$ at room temperature of $29^{\circ} \mathrm{C}$. At room temperature Blend $C$ has the highest performance in extracting oil from sample 1 . The highest performance in recovery of oil from sample 2 was observed with blend $A(66.25 \%)$. Solvent extraction process is very effective in recovering hydrocarbons oil from TBS. The use of solvents mixture greatly improved oil recovery from TBS and varies with blend composition and the operating temperature condition.
\end{abstract}

\section{Introduction}

Petroleum sludges are hydrocarbon wastes generated at crude oil production terminals (tank bottom sludge) and refineries (refinery sludge) that cause environmental pollution [1]. These sludges which are potential environmental contaminants deposited at the bottom of crude oil tankers, crude oil storage tanks and refinery storage tanks [2, 3], are generally three-phase mixtures of water, petroleum and sludge solids [4]. Speight [5], described crude oil sludge components to include non-volatile oils and additives, semisolid or solid particles formed during and after separation and storage of crude oil. They are undesirable by-products of many oil production and refining operations, but are especially common and troublesome in oilfield operations. Oil sludge consists mainly of hydrocarbons and non-hydrocarbon compounds. The hydrocarbons can be paraffin, aromatics, asphaltenes or semi-solid hydrocarbons (wax), which under certain conditions can settle out from the crude itself. The non-hydrocarbons may have been delivered with crude into the storage tank. An analysis of crude oil sludge [6] shows that greater than $90 \%$ of the sludge material is composed of the valuable hydrocarbons such as paraffin and asphaltene; a three-phase continuum containing inter-dispersed asphaltenic oil, water and solid fines recalcitrant to demulsification by heat, chemical and centrifuge. The disposal of oily sludge to the environment could lead to various toxic effects caused by these petroleum hydrocarbons (PHCs) and heavy metals. The polycyclic aromatic hydrocarbons (PAHs) contents of PHCs, are genotoxic to humans and other ecological receptors [7]. 
Several methods developed for recycling hydrocarbons from oily sludge include, among others, solvent extraction, centrifugation, surfactant treatment, pyrolysis and froth floatation [3, 818]. Solvent extraction process mixes oily wastes with solvent at desired proportions, ensures complete miscibility, and the water, solid and carbonaceous impurities are selectively rejected by the extracting solvent. Centrifugation utilizes high-speed rotation device to create a strong centrifugal force which separates components with different densities within a short time. This recovery method has not been reported widely in the literatures. Surfactants treatment on the other hand, has been widely reported [19-25]. Surfactants are generally amphiphilic compounds, having a hydrophobic end and a hydrophilic end. The hydrophilic portion enhances dissolution of the surfactant molecule in the water phase, thus increases solubility of petroleum hydrocarbons (PHCs), while the hydrophobic end causes it to gather at the interfaces to decrease the surface or interfacial tension and thus enhance the mobility of PHCs. Pyrolysis process is thermal decomposition of organic materials at high temperatures $\left(500-1000{ }^{\circ} \mathrm{C}\right)$ in an inert environment. It generates lower molecular weight hydrocarbons on condensation (liquid pyrolysis hydrocarbon fuel oil), noncondensable gases and solid char. Froth flotation, on the other hand, is a surface chemistry-based unit operation involving the capture of oil droplets by air bubbles in an aqueous slurry, suspension and collection in a froth layer.

Basically, recycling is considered most appropriate environmental friendly option for handling TBS because it allows reuse of valuable hydrocarbon oil recoverable from the sludge, reduces the disposal volume of toxic waste thereby preventing the extent of environmental contamination. The primary environmental consideration in handling oily sludge is the maximization of hydrocarbon recovery [26]. Generally, solvent extraction represents a simple but efficient method to separate oily sludge into valuable hydrocarbon and a solid or semi-solid residue with reduced volume. Various solvents such as, turpentine, methyl ethyl ketone (MEK), liquefied petroleum gas condensate (LPGC), naphtha cut, kerosene cut, n-heptane, toluene, methylene dichloride, ethylene dichloride, hexane, xylene and diethyl ether have been reported for oily sludge treatment $[12,15,16,27,28]$. However, there is dearth of information on the recovery efficiency of a blend of these solvents. The major thrust of this study therefore, is to investigate the potentials of solvent blends in recovering the hydrocarbon oils from TBS with the aim to establishing synergism in solvent blend action and as well enhance the recovery of valuable hydrocarbons from petroleum tank bottom sludge.

According to literature, the effectiveness or the ability of any liquid to dissolve, suspend or extract other materials, to form a solution without chemical change to the material depend on its solvency $[29,30]$. This indicates the capability of solvents to disperse the molecules of a solute. The relative solvency of substances has been given in terms of solubility parameter [31].

Solvent blend, a specially prepared mixture of two or more solvents combines two advantages of improving efficiency of solvent in extraction without compromising the quality and accuracy of exhibiting selective solubility behavior. It controls such properties as evaporation rate, solution viscosity, toxicity or environmental effects. According to Burke (1984) [32], the solubility behavior of blend shows additive property and can be determined mathematically for a mixture of $\mathrm{N}$ solvents by Eq. 1

$$
\gamma_{\text {mix }}=\sum_{i=1}^{N} f_{i} * H V_{i}
$$

where, $f_{\mathrm{i}}$ is volume fraction of solvent $i, H V_{i}$ is Hildebrand values for solvents $i$ obtainable from literature [33] or determined experimentally. A blend with the same solubility parameters as a single solvent will exhibit the same solubility behavior since the solubility properties are the net result of intermolecular attractions. 


\section{Materials and Method}

\section{Materials.}

The oily sludges used for this study were collected from the crude storage tanks number 3 and 5 , during tank cleaning process of Escravos Tank Farm in the Niger Delta of Nigeria. The solvents used in this study were AnalaR grade of xylene, n-hexane, cyclohexane and petroleum ether supplied by British Drug House. The various solvent blends used for the extraction was prepared as binary mixture of two solvents in volume fractions $0.2,0.4,0.6$ and 0.8 of xylene. Blend $\mathrm{A}$ is xylene-hexane, blend $\mathrm{B}$ is xylene-petroleum ether and blend $\mathrm{C}$ is xylene-cyclohexane.

\section{Determination of the Solid, Water and Hydrocarbon Oil Contents.}

The water and sediment/solid contents of the sludge samples were measured in accordance with modified methods of ASTM D95[34] and ASTM D473[34] respectively. The oil hydrocarbon content was calculated by taking the balance on fixed mass of sludge sample initially taken for the analysis.

\section{Solid/ Sediments Content.}

The test method used for the determination of the sediments in the sample was a modified Test Method for Sediment in Crude Oils and Fuel Oils by the Extraction Method [34]. Five grams (5 g) of the sludge sample was carefully weighed into a conical flask and $50 \mathrm{ml}$ of the solvent mixture added, covered with aluminium foil and shaken until the oil component was completely dissolved. The mixture was filtered using suction filtration to separate solid content. The residue on the filtered paper was washed with $10 \mathrm{ml}$ of the solvent mixture twice and dried in an electric oven at $105{ }^{\circ} \mathrm{C}$. The filter paper with the dried residue was weighed at time intervals of 15 minutes until a constant weight was obtained. The percentage solid content of the sludge was then determined using the following equation,

$$
\% \text { Solid content }=\frac{100 \mathrm{M}_{\mathrm{s}}}{5.00}
$$

where the mass of solid, $\mathrm{M}_{\mathrm{s}}$, is given by

$$
\mathrm{M}_{\mathrm{s}}=\mathrm{M}_{\mathrm{fs}}-\mathrm{M}_{\mathrm{ff}}
$$

$M_{f s}$ is the mass of solid with the filter paper while $M_{f f}$ is the mass of filter paper only.

\section{Water content.}

The water content of the sludge samples was measured by the method of ASTM D95[34]. Five grammes $(5 \mathrm{~g})$ of samples was taken and placed in extraction thimble. $75 \mathrm{ml}$ of the solvent dicloro methane was added to the mixture, distilled and the condensate collected in a trap and transferred into a separating flask. It was left for 30 minutes for the liquid layers (aqueous and organic) to separate. The water layer was then decanted into a pre-weighed measuring cylinder. The mass of the aqueous layer plus the cylinder was measured. The mass of aqueous phase $M_{w}$ and the percentage aqueous phase separated was determined using equations (4) and (5).

$$
\begin{aligned}
& M_{w}=M_{w+c}-M_{c} \\
& \% \text { Aqueous Phase }=\frac{M_{w}}{5.00} * 100
\end{aligned}
$$

where $\mathrm{M}_{\mathrm{c}}$ is the mass of measuring cylinder; $\mathrm{M}_{\mathrm{w}+\mathrm{c}}$ is the mass of measuring cylinder plus separated water. 


\section{Recovery of the hydrocarbon oil.}

The oil content of the sludge was recovered by solvent extraction. About $25 \mathrm{~g}$ of the sludge sample was mixed with $50 \mathrm{ml}$ of solvent mixture in a conical flask and shaken vigorously for about 30 minutes in a gyratory shaker. The resulting heterogeneous mixture was transferred into teflon coated centrifuge tube, centrifuged at $5000 \mathrm{rev} \mathrm{min}^{-1}$ for about 5 minutes and the supernatant oil and solvent was removed and collected in glass bottles. The reclaimed oil was concentrated by evaporating the solvent in a rotary evaporator and weighed.

Also, the oil content was evaluated by taking mass balance on the sludge sample since the oily sludge is mainly composed of water/aqueous, sediments/solids content and heavier component hydrocarbons (oil content) like wax and asphaltenes. Thus, the mass of oil extracted $\mathrm{M}_{\mathbf{o i l}}$, and the percentage oil extracted are given by equations (6) and (7).

$$
\begin{aligned}
& M_{\text {oil }}=\left[25.00-\left(M_{S}\right)-M_{w}\right] \\
& \% \text { Oil extracted }=\frac{M_{\text {oil }}}{25.00} * 100
\end{aligned}
$$

The data obtained from the variation of the blend composition were subjected to descriptive statistics.

\section{Results and Discussion}

The sludge samples characterization is reported in Table 1 . The water content was in the range of 15 and 21 percent while the non-volatile hydrocarbon oil content was in the range of 51 and 57.1 percent. This is similar to Ploiesti Romania and Burgass Bulgaria sludge reported [35] to have 54.8 and 54.3 weight percent oil content respectively. The specific gravity and API gravities of the samples at $25{ }^{\circ} \mathrm{C}$ were 0.942 and 15.737 respectively, for sample 1 and 0.885 and 25.193 respectively, for sample 2 .

\begin{tabular}{|c|c|c|}
\hline Property & Sludge Sample 1 & Sludge Sample 2 \\
\hline Water content $[\%]$ & 15.5 & 20.4 \\
\hline Solid content $\quad[\%]$ & 23.4 & 9.3 \\
\hline Oil content $\quad[\%]$ & 51.8 & 57.1 \\
\hline Volatile content $[\%]$ & 9.6 & 13.2 \\
\hline
\end{tabular}

Table 1. Sludge Sample characterization results.

The percentage of oil extracted from the sludge samples, as reported in Table 2, varies with the blend composition defined by solubility parameter of the blend. A decrease in the volume fraction $\left(f_{1}\right)$ of solvent $\mathbf{S}_{\mathbf{1}}$ (xylene) decreases the blend solubility parameter. As the solubility parameter increases the amount of oil extracted increases until an optimum value of $66.25 \%$ was attained at solubility parameter, $\gamma_{\text {mix }}$ of 16.22 for untreated crude oil sludge (Sample 2) and later decreases sharply. Thus, there is an optimum blend composition for the extraction of oil from the crude sample. For the treated crude sludge sample, the optimum oil extraction value of $54.475 \%$ at solubility parameter, $\gamma_{\text {mix }}$, of 16.88 solvent blend was obtained corresponding to volume-fractional composition of $60 \%$ xylene. The amount of oil extracted from the untreated sample is higher than those from treated sample. This suggests possibility of loss of part of the oil content to the applied treatment. The optimum value of oil recovery depends on the previous chemical treatment given to the crude oil sludge.

Similarly, the solubility parameter of blends $B$ and $C$ decreases as the volume fraction of solvent $\mathrm{S}_{1}$ (xylene) decreases. The extraction of oil from untreated sludge by blend $B$ shows an optimum recovery of $60.800 \%$ at blend solubility parameter, $\gamma_{\text {mix }}$ of 17.36 , corresponding to $\mathrm{f}_{1}$ of 
0.60 xylene. For treated sample, as the solubility parameter increases the oil extracted increases until it attains a peak value of $60.325 \%$ at $\gamma_{\text {mix }}$ of 16.94 corresponding to volume fraction of 0.4 xylene.

The optimum extraction of oil from sample 2 by blend $\mathrm{C}$ (xylene-cyclohexane mixture) is $63.350 \%$, which occurred at fractional volume $\mathrm{f}_{1}=0.5$ for xylene while peak value of oil recovery from sample 1 occurred at volume fraction of xylene, $f_{1}=0.5$ and the value is $61.100 \%$. Generally, the results show that the blend compositions do affect the amount of oil extractable from the crude oil sludge.

Zubaidy and Abouelnasr [16] reported the highest oil recovery of 39\% and 32\% using MEK and LPGC in solvent extraction of hydrocarbon oil from TBS. Also, Chang et al. [8] observed a maximum production rate of $51.61 \mathrm{wt} . \%$ of PHCs hydrocarbons (mainly low-molecular-weight paraffins and olefins,) at $440{ }^{\circ} \mathrm{C}$, using pyrolysis process to treat oily sludge. These are lower than that observed in this present report. However, the findings of Ramaswamy et al. [14] using froth flotation treatment for oil-water separation from oily sludge, showed an oil recovery of up to 55\% at the optimal flotation conditions. Similarly, Schmidt and Kaminsky [36] found that at temperature range of 460 to $650 \circ \mathrm{C}, 70-84 \%$ oil were recoverable from sludge by a fluidized bed reactor. These are comparable to that observed in this present study. It is however worth noting that apart from high recovery, the hydrocarbon oils are obtained in near native form by solvent extraction technique relative to other methods.

Table 2. Effects of Blend Composition on Extraction of Oil from crude oil Sludge Samples.

\begin{tabular}{|c|c|c|c|c|c|c|c|}
\hline \multirow[t]{2}{*}{$\mathbf{f}_{1}$} & \multirow[t]{2}{*}{$\mathbf{f}_{2}$} & \multicolumn{2}{|c|}{ Blend A } & \multicolumn{2}{|c|}{ Blend B } & \multicolumn{2}{|r|}{ Blend C } \\
\hline & & $\gamma_{\text {mix }}$ & $\begin{array}{c}\text { Mean Oil } \\
\text { Extracted [\%] }\end{array}$ & $\gamma_{\text {mix }}$ & $\begin{array}{c}\text { Mean Oil } \\
\text { Extracted } \\
{[\%]}\end{array}$ & $\gamma_{\text {mix }}$ & $\begin{array}{c}\text { Mean Oil } \\
\text { Extracted [\%] }\end{array}$ \\
\hline \multicolumn{8}{|c|}{ Sample 1} \\
\hline 1.0 & 0.0 & 18.20 & $52.400 \pm 0.455$ & 18.20 & $52.400 \pm 0.455$ & 18.20 & $52.400 \pm 0.394$ \\
\hline 0.8 & 0.2 & 17.54 & $51.525 \pm 1.187$ & 17.78 & $45.800 \pm 1.871$ & 17.92 & $52.600 \pm 1.012$ \\
\hline 0.6 & 0.4 & 16.88 & $54.475 \pm 3.035$ & 17.36 & $55.425 \pm 3.254$ & 17.64 & $53.950 \pm 0.976$ \\
\hline 0.5 & 0.5 & 16.55 & $49.900 \pm 0.258$ & 17.15 & $57.625 \pm 1.936$ & 17.50 & $61.100 \pm 1.155$ \\
\hline 0.4 & 0.6 & 16.22 & $54.100 \pm 2.553$ & 16.94 & $60.325 \pm 1.118$ & 17.36 & $58.100 \pm 4.986$ \\
\hline 0.2 & 0.8 & 15.56 & $51.325 \pm 0.377$ & 16.52 & $56.925 \pm 1.159$ & 17.08 & $44.125 \pm 6.095$ \\
\hline 0.0 & 1.0 & 14.90 & $50.500 \pm 0.753$ & 16.10 & $58.300 \pm 0.483$ & 16.80 & $35.125 \pm 0.998$ \\
\hline \multicolumn{8}{|c|}{ Sample 2} \\
\hline 1.0 & 0.0 & 18.20 & $45.448 \pm 0.246$ & 18.20 & $45.448 \pm 0.246$ & 18.20 & $45.448 \pm 0.213$ \\
\hline 0.8 & 0.2 & 17.54 & $53.725 \pm 3.366$ & 17.78 & $51.875 \pm 5.210$ & 17.92 & $52.050 \pm 1.244$ \\
\hline 0.6 & 0.4 & 16.88 & $66.250 \pm 0.265$ & 17.36 & $56.050 \pm 1.439$ & 17.64 & $55.325 \pm 0.952$ \\
\hline 0.5 & 0.5 & 16.55 & $57.975 \pm 0.403$ & 17.15 & $56.700 \pm 5.452$ & 17.50 & $63.350 \pm 0.687$ \\
\hline 0.4 & 0.6 & 16.22 & $54.025 \pm 5.398$ & 16.94 & $60.800 \pm 1.918$ & 17.36 & $52.075 \pm 1.143$ \\
\hline 0.2 & 0.8 & 15.56 & $47.375 \pm 1.744$ & 16.52 & $55.800 \pm 3.212$ & 17.08 & $52.125 \pm 0.554$ \\
\hline 0.0 & 1.0 & 14.90 & $44.750 \pm 0.404$ & 16.10 & $60.488 \pm 0.527$ & 16.80 & $56.450 \pm 1.577$ \\
\hline
\end{tabular}

Blend A consists of xylene and hexane; blend B consists of xylene and petroleum ether; blend C consists of xylene and cyclohexane. $f_{1}$ is volume fraction of xylene; $f_{2}$ is the volume fraction of the other component in the blend $\left[f_{2}=1-f_{1}\right]$ and $\gamma_{\text {mix }}$ represents the solubility parameters of the blend. 
Table 3 shows the summary of optimum values of oil extracted by the various solvents and blends from sludge samples. Single solvents, xylene and hexane extracted $59.00 \%$ and $44.20 \%$ respectively from sample 2 while the use of their mixture extracted $66.250 \%$ equivalent to about $45.16 \%$ increase in oil recovery from the same sample 2 . A similar trend ensued for sample 1 with Blend C (xylene-cyclohexane mixture) extracting oil maximally from sample 1.

Table 3. Summary of Optimum Values of Oil Extracted by Various Blends from Sludge Samples.

\begin{tabular}{|l|c|c|c||c|c|c|}
\hline \multirow{2}{*}{ Blend } & \multicolumn{2}{|c||}{ Sample 1 (Treated sample) } & \multicolumn{2}{c|}{ Sample 2 (Untreated Sample) } \\
\cline { 2 - 7 } & $\begin{array}{c}\text { Max. Oil } \\
\text { extracted } \\
{[\%]}\end{array}$ & $\begin{array}{c}\text { Optimum } \\
\text { Blend } \\
\text { Composition }\end{array}$ & $\boldsymbol{\gamma}_{\text {mix }}$ & $\begin{array}{c}\text { Max. Oil } \\
\text { extracted } \\
{[\%]}\end{array}$ & $\begin{array}{c}\text { Optimum Blend } \\
\text { Composition }\end{array}$ & $\gamma_{\text {mix }}$ \\
\hline $\begin{array}{l}\text { Blend } \\
\boldsymbol{A}\end{array}$ & 54.475 & $\begin{array}{c}\mathrm{f}_{1}=0.60, \\
\mathrm{f}_{2}=0.40\end{array}$ & 16.88 & 66.250 & $\begin{array}{c}\mathrm{f}_{1}=0.40 \\
\mathrm{f}_{2}=0.60\end{array}$ & 16.22 \\
\hline $\begin{array}{l}\text { Blend } \\
\boldsymbol{B}\end{array}$ & 60.325 & $\begin{array}{c}\mathrm{f}_{1}=0.60 \\
\mathrm{f}_{2}=0.40\end{array}$ & 16.94 & 60.800 & $\begin{array}{c}\mathrm{f}_{1}=0.40 \\
\mathrm{f}_{2}=0.60\end{array}$ & 17.36 \\
\hline $\begin{array}{l}\text { Blend } \\
\text { C }\end{array}$ & 61.100 & $\begin{array}{c}\mathrm{f}_{1}=0.50 \\
\mathrm{f}_{2}=0.50\end{array}$ & 17.50 & 63.350 & $\begin{array}{c}\mathrm{f}_{1}=0.50 \\
\mathrm{f}_{2}=0.50\end{array}$ & 17.50 \\
\hline Single Solvent & 52.4 & 1.0 & 18.2 & 59.00 & 1.0 & 18.2 \\
\hline XY & 51.2 & 1.0 & 14.9 & 44.20 & 1.0 & 14.9 \\
\hline HE & 58.2 & 1.0 & 16.1 & 61.20 & 1.0 & 16.1 \\
\hline PE & 33.6 & 1.0 & 16.8 & 45.64 & 1.0 & 16.8 \\
\hline CH & & & & & & \\
\hline
\end{tabular}

The performance of blend reflected the relative polarity index of the constituent solvent. The polarity indexes $[37,38]$ of constituent solvent are xylene $(2.5)$, petroleum ether $(0.1)$, cyclohexane $(0.2)$ and hexane (0.1). At optimum performance, this gave a relative polarity index of blend $\mathrm{A}$ (1.54), blend B (1.06) and blend C (1.35). Thus blends A and C display high potential for oil extraction from the TBS. Similarly, xylene and petroleum ether single solvents extracted high percentage of oil from the sludge which equally follows the solubility parameter trend. There is synergism in the solvent blends, extracting higher percentage oil over and above the single solvents in all the cases. Summarily, the higher the polarity index or solubility parameter of the solvent, the greater the relative performance of the solvent and solvent blend for extraction hydrocarbons from the TBS.

Solvent extraction recovery of the hydrocarbon constituents of the sludge apart from maximizing the hydrocarbon exploitation in petroleum industry, it equally enhances the environmental quality. The greater the percentage of oil extracted the lower the volume of TBS to be disposed into the environment, hence, the higher waste reduction level. The waste reduction attainable in sample 1 is about $63 \%$, using xylene:hexane volumetric fraction of 0.60:0.40. Similarly, for sample 2, the waste reduction by blend $\boldsymbol{A}$ is above $67 \%$ blend's volumetric ratio of 0.60:0.40. These will make a significant impact on the environmental quality because TBS constitute an unwholesome and environmentally unacceptable pollution on the environment due to the toxic level of the hydrocarbon constituents of crude oil. 


\section{Conclusion}

There is synergism in xylene based solvent blends with attendant enhancement in the recovery efficiency of hydrocarbon oil content of the TBS. Solvent extraction process is very effective in recovering hydrocarbons oil from the tank bottom sludge. This waste management option successfully separated the sludge samples into its various constituent (i.e. water, solid and oil) which can be channeled to appropriate stream for proper management.

Application of solvent blends in extraction (SE) treatment of petroleum oil from tank bottom sludge greatly reduce its pollution effects on the environment and hence significant in environmental sustainability management around petroleum refineries. Recyclable hydrocarbon oil so obtained can be channeled into petrochemical or refinery industry.

\section{Acknowledgement}

The authors are thankful to Department of Petroleum Resources (DPR), Nigeria, and Chevron Nigeria Limited for providing the samples, Department of Chemical Engineering, Obafemi Awolowo University and Department of Chemistry and Industrial Chemistry, Bowen University, Iwo for providing the infrastructure to carry out this study.

\section{References}

[1] I. Badrul. Petroleum sludge, its treatment and disposal: A review, Int. J. Chem. Sci. 13(4) (2015) 1584-1602.

[2] M.H. Greg, A.H. Robert, A. Zdenek, Paraffinic sludge reduction in crude oil storage tanks through the use of shearing and resuspension, Acta Montanistica Slovaca Ročník. 9(3) (2004) 184-188.

[3] T.M.S. Lima et al., Evaluation of bacterial surfactant toxicity towards petroleum degrading microorganisms, Bioresour. Technol. 102 (2011) 2957-2964.

[4] B. Sander, F. Hovemann, K. Scherling, Dewatering of petroleum-containing sludges with recovery of the oil component, U.S. Patent No. 4417 976, 29 Nov., 1983.

[5] J.G. Speight, Handbook of petroleum analysis, Wiley Interscience, New York, 2001.

[6] R.A. Tahhan et al., Enhancing the biodegradation of total petroleum hydrocarbons in oily sludge by a modified bioaugmentation strategy, International Biodeterioration and Biodegradation. 65(1) (2011) 130-134.

[7] S.J. Robertson et al., Petroleum hydrocarbon contamination in boreal forest soils: A mycorrhizal ecosystems perspective, Biol. Rev. 82 (2007) 213-240.

[8] C.Y. Chang et al., Major products obtained from the pyrolysis of oil sludge, Energy Fuel. 14 (2000) 1176-1183.

[9] A.A. Mansur et al., Recovery and characterization of oil from waste crude oil tank bottom sludge from Azzawiya Oil Refinery in Libya, J. Adv. Chem. Eng. 5(118) (2015). Doi:10.4172/2090-4568. 1000118

[10] J.L. Shie et al., Pyrolysis of oil sludge with additives of sodium and potassium compounds, Resour. Conserv. Recycl. 39 (2003) 51-64

[11] K.R. Edwards, J.E. Lepo, M.A. Lewis, Toxicity comparison of biosurfactants and synthetic surfactants used in oil spill remediation to two estuarine species, Mar. Pollut. Bull. 46 (2003) 1309-1316.

[12] M.H.P. Gazineu et al., Radioactivity concentration in liquid and solid phases of scale and sludge generated in the petroleum industry, J. Environ. Radioact. 81 (2005) 47-54. 
[13] A. Cambiella et al., Centrifugal separation efficiency in the treatment of waste emulsified oils, Chem. Eng. Res. Des. 84 (2006) 69-76.

[14] D. Ramaswamy, D.D. Kar, S. De, A study on recovery of oil from sludge containing oil using froth flotation, J. Environ. Manage. 85 (2007) 150-154.

[15] A.Y. El-Naggar et al., Petroleum cuts as solvent extractor for oil recovery from petroleum sludge, J. Petrol. Technol. Altern. Fuels. 1 (2010) 10-19.

[16] E.A.H. Zubaidy, D.M. Abouelnasr, Fuel recovery from waste oily sludge using solvent extraction process, Saf. Environ. 88 (2010) 318-326.

[17] D.G. Nahmad, Method to recover crude oil from sludge or emulsion, United States Patent, US 8,197,667 B2, 2012.

[18] A. Al-Otoom et al., Bitumen recovery from Jordanian oil sand by froth flotation using petroleum cycles oil cuts, Energy. 35 (2010) 4217-4225.

[19] C.N. Mulligan, Recent advances in the environmental applications of biosurfactants, Curr. Opin. Colloid Interface Sci. 14 (2009) 372-378.

[20] C.L. Chin et al., Biosurfactant-enhanced removal of total petroleum hydrocarbons from contaminated soil, J. Hazard. Mater. 167 (2009) 609-614.

[21] C. Calvo et al., Application of bio emulsifiers in soil oil bioremediation processes, Sci. Total Environ. 407 (2009) 3634-3640

[22] A.A. Abdel-Azim et al., Demulsifier systems applied to breakdown petroleum sludge, J. Petrol. Sci. Eng. 78 (2011) 364-370.

[23] T.M.S. Lima et al., Evaluation of bacterial surfactant toxicity towards petroleum degrading microorganisms, Bioresour. Technol. 102 (2011) 2957-2964.

[24] T.M.S. Lima et al., Oil recovery from fuel oil storage tank sludge using bio surfactants, J. Bioremed. Biodegrad. (2011) 1-5.

[25] X. Long et al., Application of rhamnolipid as a novel biodemulsifier for destabilizing waste crude oil, Bioresour. Technol. 131 (2013) 1-5.

[26] API, Environmental guidance document: Onshore solid waste management in exploration and production operations, American Petroleum Institute (API), Washington DC, 1989.

[27] D.S. Meyer et al., Oil tank sludge removal method, United States Patent, US 2006/0042661 A1, 2006.

[28] E.A. Taiwo, J.A. Otolorin, Oil recovery from petroleum sludge by solvent extraction, J. Pet. Sci. Technol. 27 (2009) 871-879.

[29] A.P. Kuriakose, S.B.M. Kochi, Bituminous paints from refinery sludge, J. Surf. Coat. Technol. 145(1-3) (2001) 132-138.

[30] P.H. Ogeden, Chemical in oil industry: Developments and applications, Akzo Chemie UK Ltd, Royal Society of Chemistry, 1991.

[31] J. Hildebrand, R. L. Scott, The solubility of Non-electrolytes, third ed, Prentice-Hall, New York, 1950

[32] J. Burke, Solubility parameters: Theory and application, J. Paint Technol. 39 (1984) 505.

[33] C. Hanson, Solvent extraction, Chemical Engineering, McGraw-Hill, U.S.A., 1967.

[34] ASTM, Test method for sediment in crude oils and fuel oils by the extraction method, Annual Book of ASTM Standards, West Conshohocken: ASTM International. 5(1) 2005. 
[35] J. Kukacka, I. Hlasensky, Investigation and treatment of oil lagoons: Selected technological approaches, International workshop on the remediation of tar and acid tar contaminated sites. Chemnitz., 2006.

[36] H. Schmidt, W. Kaminsky, Pyrolysis of oil sludge in a fluidized bed reactor, Chemosphere. 45 (2001) 285-290.

[37] R. Christian, T. Welton, Solvents and solvent effects in organic chemistry, fourth Edition, Wiley-VCH Verlag GmbH \& Co, KGaA, 2011.

[38] D. Harris, Quantitative chemical analysis, ninth ed., W.H. Freeman and Company, New York, 2015. 